\title{
Detection of micrometastases by flow cytometry in sentinel lymph nodes from patients with renal tumours
}

\author{
Ciputra Adijaya Hartana ${ }^{1,5}$, Johan Kinn ${ }^{1,5}$, Robert Rosenblatt ${ }^{2}$, Stefan Anania ${ }^{3}$, Farhood Alamdari ${ }^{4}$, \\ Hans Glise ${ }^{1}$, Amir Sherif ${ }^{2}$ and Ola Winqvist ${ }^{*}, 1$ \\ ${ }^{1}$ Karolinska Institutet, Department of Medicine Solna, Unit of Immunology and Allergy, Karolinska University Hospital, 17176 \\ Stockholm, Sweden; ${ }^{2}$ Department of Surgical and Perioperative Sciences, Urology and Andrology, Umeå University, 90185 Umeå, \\ Sweden; ${ }^{3}$ Department of Urology, Stockholm South General Hospital, Karolinska Institutet, Stockholm, Sweden and ${ }^{4}$ Department of \\ Urology, Västmanland Hospital, Västerås, Sweden
}

Background: Stage is an important prognostic factor in renal tumours and dissemination to regional lymph nodes is associated with poor outcomes. Lymph nodes are routinely assessed by immunohistochemistry and microscopic evaluation, a timeconsuming process where micrometastases might go undiagnosed. We evaluate an alternative method for detecting metastatic cells in sentinel nodes (SNs) by flow cytometry.

Methods: A total of 15 nodes from 5 patients diagnosed with renal tumours were analysed by flow cytometry. Staining for the intracellular marker cytokeratin 18 (CK18) with the surface markers carbonic anhydrase IX (CA9) and Cadherin 6 were used in flow cytometry analysis. Peripheral blood mononuclear cells (PBMCs) with the addition of known concentrations of cancer cell lines were analysed to investigate the sensitivity of micrometastasis detection.

Results: Stability of the assay was marked by low intra-assay variability (coefficient of variance $\leqslant 16 \%$ ) and low inter-assay variability $\left(R^{2}=0.9996-1\right)$. Eight nodes in four patients were positive for metastasis; six of them were considered being micrometastatic. These metastases were undetected by routine pathology and the patients were restaged from pN0 to pN1.

Conclusions: Flow cytometry is able to detect micrometastases in lymph nodes of renal tumour patients that were undetected under H\&E examination.

Kidney cancer or renal cell carcinoma (RCC) is the fourteenth most common cancer in the world, and the global incidence in 2008 was 273.518 (Ferlay et al, 2010). It is well established that the presence of lymph node metastases significantly affects the prognosis of RCC (Vasselli et al, 2001; Pantuck et al, 2003). The capacity of tumours to metastasise is a characteristic ability acquired during tumour genesis (Hanahan and Weinberg, 2011). Renal cancer cells metastasise either directly via haematogenous dissemination or by spread to draining regional lymph nodes. Currently, detection of metastatic cells in lymph nodes is routinely performed by visual examination of haematoxylin and eosin (H\&E)-stained slices under the microscope by a pathologist. However, this process is time consuming and micrometastases (MICs) might be missed. It was previously demonstrated that $19.4 \%$ of nodes that were MIC free under H\&E examination were shown to be positive for MICs by immunohistochemistry (IHC) (Tschmelitsch et al, 2000). Weaver et al (2003) described a method to examine multiple IHC cytokeratin-stained sections using automated computer-assisted image analysis, reporting additional detection of MICs as compared with IHC. Sensitivity

\footnotetext{
*Correspondence: Dr O Winqvist; E-mail: ola.winqvist@karolinska.se

${ }^{5}$ These authors contributed equally to this work.
} 
can thus be increased by examining additional sections from every node (Lim et al, 2013), but this approach is too labour intensive for routine use when a large amount of nodes should be examined. In addition, MICs can potentially still be missed as only $5 \mu \mathrm{m}$ thick sections of the whole lymph node are routinely examined, representing less than $\sim 0.1 \%$ of the node.

Several attempts have been made to use alternative techniques to investigate the presence of metastatic cells in lymph nodes. Metastatic cells can be detected using reversed transcriptase-PCR (RT-PCR) (Haince et al, 2010). The method is highly sensitive, but mRNA is sensitive to degradation during storage and transportation (Weigelt et al, 2004). This induces the risk of receiving false negative results. In addition, some genes are upregulated during storage, thus generating false positive results (Benoy et al, 2006). Moreover, contamination may possess a problem in routine practice when multiple samples are handled in parallel, as RTPCR detects very low levels of transcripts.

Flow cytometry has the ability to detect several parameters at the single-cell level. These multiple parameters may be analysed in combination with size (forward scatter) and complexity (side scatter) properties of each tumour cell studied. Tumour cells can also be detected by labelling of cytokeratin with fluorophoreconjugated antibodies, and labelling of DNA with propidium iodide (PI) (Leers et al, 2002).

We have recently described a method for detecting colon cancer cells in single-cell suspensions derived from lymph nodes by staining with multiple surface markers and detection by flow cytometry (Karlsson et al, 2008). In this method, we combine the staining method for intracellular and surface tumour antigens. Staining of intracellular markers is more cumbersome and may increase background. However, staining of surface markers has some limitations. Surface markers may be sensitive to enzymatic degradation that is a part of protocols to obtain single-cell suspensions. In addition, the expression of surface antigens may be downregulated because of genetic instability of tumour cells, as previously observed (Karlsson et al, 2008).

The differential expression of intracellular antigen, cytokeratins in various types of carcinomas makes them useful staining targets for IHC to identify tumour cells, a practice widely used for different cancers. Subtypes of RCCs express varying patterns of cytokeratins (Langner et al, 2004), but staining for cytokeratin 18 (CK18) is the most commonly used for routine IHC evaluation of RCC (Messai et al, 2010). Surface markers can potentially also be used to identify renal tumour cells. The expression of carbonic anhydrase 9 (CA9), also known as G250 or MN, is highly prevalent in RCC, and the expression is considered as a prognostic factor (Soyupak et al, 2005). This surface antigen can readily be detected by flow cytometry ( $\mathrm{Li}$ et al, 2001). Cadherin 6, a cell adhesion molecule found in the cell surface, is frequently used in conventional RCC (Li et al, 2005), and is also suggested as a new prognostic factor in RCC (Marshall, 2005).

An alternative method to evaluate the presence of metastases within lymph nodes needs to be developed. We therefore set up an experiment to detect metastatic cells of renal tumours by flow cytometry by combining a surface staining of CA9, Cadherin 6, and intracellular staining of CK18. In this study, we analysed 15 nodes from patients diagnosed with renal tumours with different pathological characteristics.

\section{MATERIALS AND METHODS}

Patients. Five patients diagnosed with renal tumours were included in this study. Patients 1, 4, and 5 were diagnosed with clear cell carcinoma, with patient 4 having mixed papillary renal cancer pathological feature, patient 2 had a renal oncocytoma, and patient 3 was diagnosed with mucinous tubular and spindle cell carcinoma. Clear cell carcinoma and mucinous tubular and spindle cell carcinoma are classified to be malignant renal tumours, whereas renal oncocytoma is a benign renal tumour (Lopez-Beltran et al, 2009). Written informed consent was given, and the study was approved by the local ethical committee, EPN-Stockholm (dnr: 2014/200-32).

Lymph node acquisition. Lymph nodes were obtained during nephrectomy by sentinel node (SN) detection utilising injection of $80 \mathrm{MBq}$ radioactive tracer ${ }^{99} \mathrm{~m} \mathrm{Tc}$ around the primary tumour intraoperatively. A handheld gamma probe was used to evaluate collected specimens, according to the method previously described (Bex et al, 2011; Sherif et al, 2012). Each identified node was cut longitudinally in half, one piece dedicated for conventional pathological analysis (H\&E and IHC), and the other for parallel analysis by flow cytometry. For flow cytometry, tissue samples were immediately put in RPMI medium and kept on ice until preparation and staining. Single-cell suspensions were made by gentle pressure with a loose-fitting glass homogeniser as previously described (Marits et al, 2006) for flow cytometry. Results of histopathology staging were unknown at the time of flow cytometric analyses.

Primary tumour samples and PBMCs. Samples of primary tumours were collected during nephrectomy and used as positive controls. Buffy coats were received from healthy controls and peripheral blood mononuclear cells (PBMCs) were isolated by separation on a Ficoll-Paque gradient and washed twice in phosphate-buffered saline (PBS), as described previously (Ulmer et al, 1984).

Cell culture. The human renal cancer cells lines RCC4, ACHN-3, and CAKI-6 were cultured in RPMI 1640 media (Sigma, Stockholm, Sweden), supplemented with $10 \%$ bovine growth serum (BGS), $1 \%$ penicillin/streptomycin (Hyclone, Uppsala, Sweden), and $1 \%$ L-glutamine (Hyclone). The cells were detached using Trypsin $0.25 \%$ and EDTA $1 \%$ (Invitrogen, Stockholm, Sweden). Before flow cytometric analyses, cells were detached with trypsin $12 \mathrm{~h}$ before the experiment, split $1: 2$, and kept in an incubator to allow regeneration of surface markers. Immediately before analyses, cells were incubated in $2 \%$ EDTA on ice for $15 \mathrm{~min}$ and then gently resuspended for detachment.

Identification of renal cancer cells in mixed cultures. Detection of renal cancer cells was investigated in PBMCs mixed with RCC cells (ACHN3, CAKI6, and RCC4) and from sentinel lymph nodes from patients with renal tumours using flow cytometry. Renal cancer cells were added to PBMCs and diluted in steps of three $(1 \%, 0.33 \%$, and $0.11 \%$, respectively) and kept in $200 \mu$ l of staining buffer ( $2 \%$ PBS, $0.01 \%$ BGS, and $0.02 \%$ Sodium Azide). The PBMCs alone were used in parallel as negative control. Samples were supplemented with $15 \%$ human serum (Sigma) for 10 min to block Fc-receptors. Antibodies for surface staining were added and incubated for $30 \mathrm{~min}$ at room temperature. After washing in staining buffer, cells were fixed using $200 \mu$ l Cytofix/Cytoperm (BD, Stockholm, Sweden) for $20 \mathrm{~min}$ at $4{ }^{\circ} \mathrm{C}$. Cells were washed in staining buffer supplemented with $0.3 \%$ Saponin (Sigma) and resuspended in $200 \mu \mathrm{l}$ of permeabilisation buffer. Antibody for intracellular staining was added and incubated for $30 \mathrm{~min}$, and finally the samples were washed 2 times before analysis. Antibodies used were: anti-Cadherin 6 (PE) (R\&D Systems, Abingdon, UK) clone: 27909, anti-CA9 (APC) (R\&D Systems) clone: 303123, and anti-cytokeratin 18 (FITC) (Life Technologies, Stockholm, Sweden) clone: DC-10. Isotype-matched controls used were anti-IgG (FITC), anti-IgG (APC), and anti-IgG (PE) from each respective manufacturer.

Analyses were performed on FACS Aria and FACS Fortessa flow cytometer (BD Biosciences, Stockholm, Sweden) using the FACSDiva software (BD Biosciences) and FlowJo v.10 (FlowJo Enterprise, Ashland, OR, USA). Recordings of 1.000.000 
events were collected. Gating was set to exclude cell debris, as determined by forward and side scatter properties on a density plot. Positive events were identified in dot plots of fluorescence $v s$ SSC properties for each marker respectively and displayed on a log-scale. The definite percentages of positive cells were calculated from percentage of positive cells deducted from background percentages acquired by isotype control.

\section{RESULTS}

Detection of tumour cell markers of RCC. We investigated three different RCC cell lines, RCC4, ACHN3, and CAKI6, for the expression of CK18, CA9, and Cadherin 6 by flow cytometry. The cell line RCC4 stained highly positive for CK18 and CA9 (Figure 1). However, the staining of Cadherin 6 showed a more continuous pattern, thus resulting in a less clear separation of positive events (Figure 1). However, when analysed in dot plots, $>90 \%$ of RCC 4 cells could be identified as positive for Cadherin 6 (data not shown).

Regarding the renal cancer cell lines ACHN3 and CAKI6, they stained highly positive for CK18 (Figure 1). However, none of these cell lines demonstrated expression of CA9 and Cadherin 6 (Figure 1).

Thus, we conclude that the intracellular marker CK18 is expressed at high levels in all three cell lines and that the cell surface markers CA9 and Cadherin 6 are expressed to a variable extent.
Detection of RCC cells in a mixed leukocyte environment. In order to test whether RCC cells could be detected by flow cytometry in a mixed environment of leukocytes using specific antibodies, we simulated the environment in a lymph node by adding decreasing numbers of renal cancer cells into PBMCs. The percentages of positive cells in each samples showed that all three markers CK18, CA9, and Cadherin 6 could be detected from $1 \%$ to $0.011 \%$ of added RCC4 cancer cell line with low background staining (Figure 2A). The percentages of added compared with the number of detected cells were analysed by regression analysis where regression coefficients above 0.97 indicate a linear and reliable detection of the three markers CK18, CA9, and Cadherin 6 from 0.011 to $1 \%$ added RCC4 cells (Figure 3).

When ACHN3 and CAKI6 cells were investigated, staining of CA9 and Cadherin 6 was not reliable (Figure 2B and C), consistent with the low expression of both markers in ACHN3 and CAKI6 cells (Figure 1). Unspecific background staining was shown to be $<0.008 \%$ (data not shown) from isotype control, thus indicating a very low level of false positives.

Stability of assay. As RCC4 expresses all of the three tumourassociated antigens with reliable detections (Figures 2 and 3), and RCC4 cells are of carcinoma origin that constitutes 90\% of all renal cancer cases, we continued to focus on this cell line for evaluation of the assay. Next, we set out to analyse the intra- and inter-assay variability by using the spiking experiments. Before analysis, samples were split into 10 aliquots and analysed separately for intra-assay variability. In addition, each sample
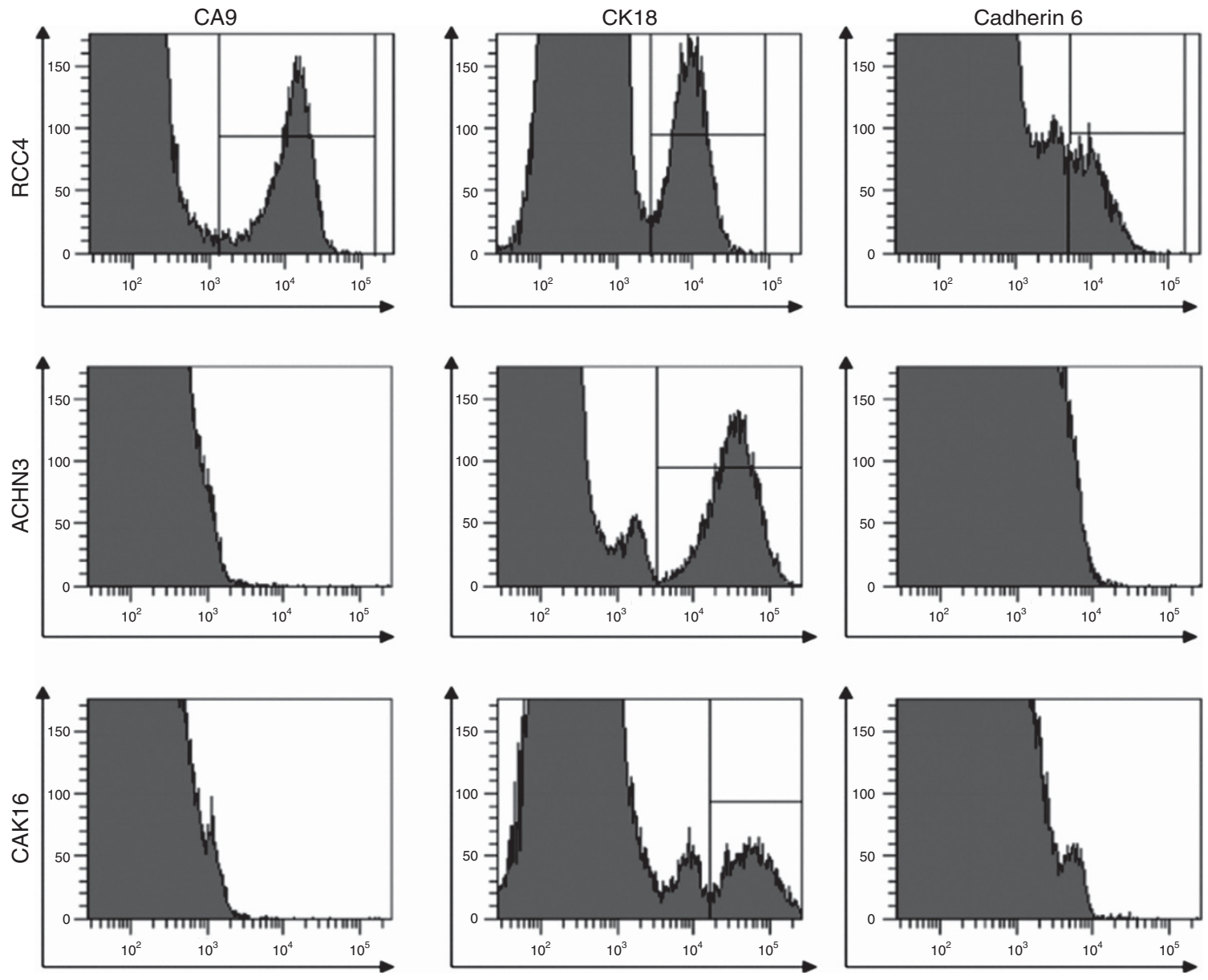

Figure 1. Flow cytometric detection of the three tumour-associated markers CK18, CA9, and Cadherin 6 in three different renal cancer cell lines, RCC4, ACHN3, and CAKI6. The y axis was set to show for the count of positive events. Gating for positive events was made based on isotype controls. 
A

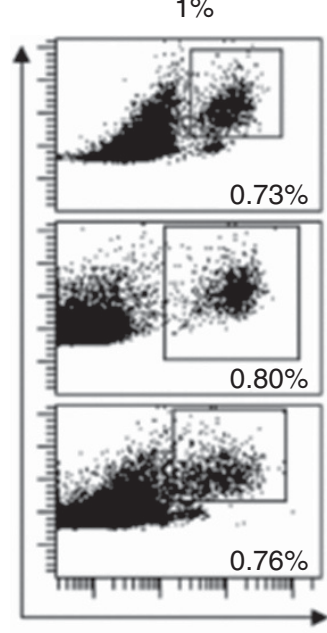

B

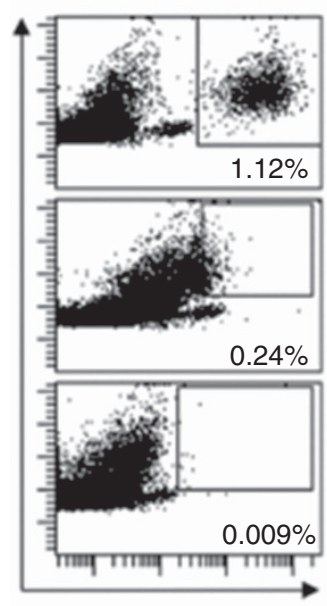

C

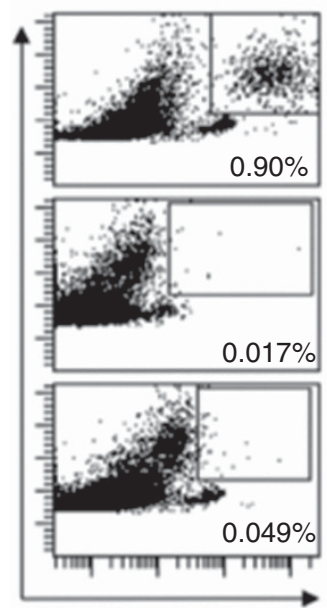

$0.33 \%$
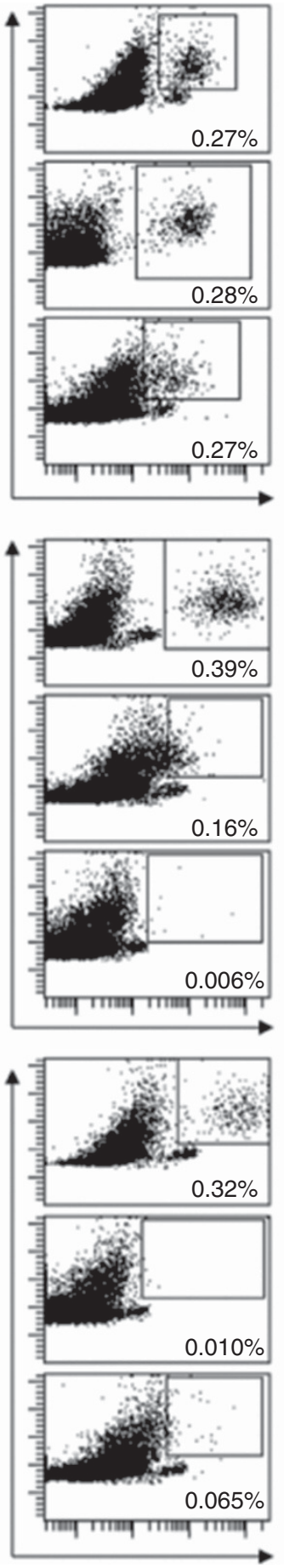

$0.11 \%$
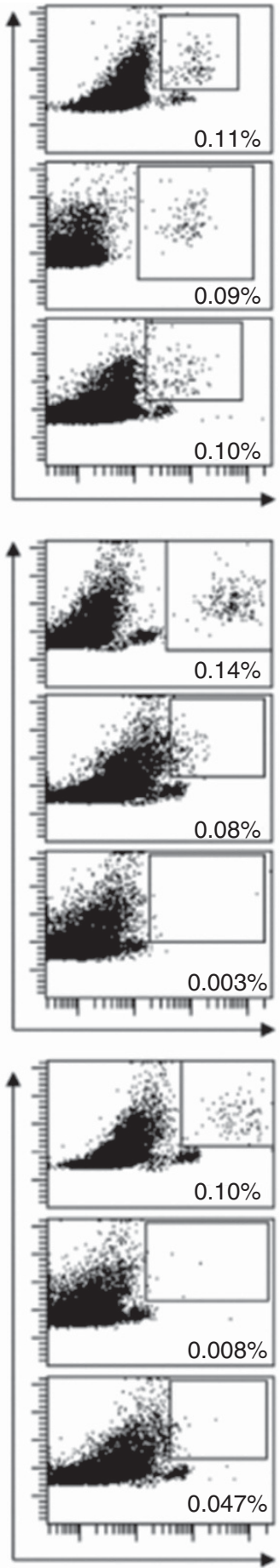

$0 \%$
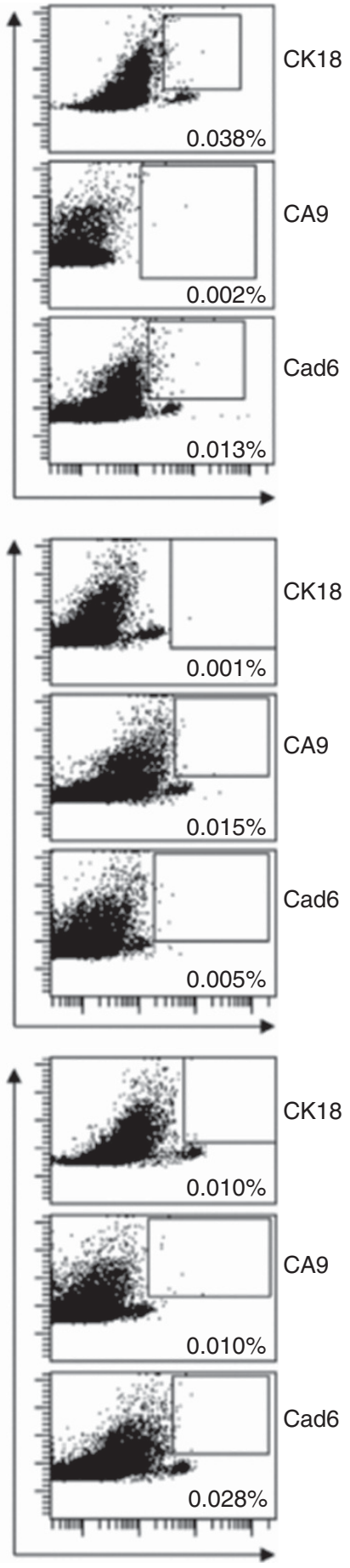

Figure 2. Flow cytometric detection of cancer cells by staining for the tumour-associated cell surface markers CA9 and Cadherin 6, and the intracellular marker CK18. Cultured cancer cells were spiked to PBMCs at a concentration of 1\%, and three-fold stepwise dilution series were prepared, resulting in concentrations of $1 \%, 0.33 \%$, and $0.11 \%$. Samples of PBMCs alone were used to detect background staining. The percentages show the amount of positive events for staining of the renal cancer cell line RCC4, visualised by plotting each marker ( $x$ axis) vs SSC properties (y axis) and gated based on isotype control (A). The same experiment was carried out by analysing the additional cell line CAKI6 (B) and $\mathrm{ACHN} 3$ respectively $(\mathbf{C})$ respectively.

was reanalysed after $\sim 8 \mathrm{~h}$ for inter-assay variability. The results of the two acquisitions showed that the intra-assay coefficient of variance $(\mathrm{CV})$ was $<16 \%$, indicating that the detection is reliable (Table 1).

The inter-assay variability between two time point acquisitions was analysed using linear regression. Percentage of acquired cells from the first run $v s$ percentage of acquired cells from the second run was evaluated. The correlation coefficient $R^{2}$ fell into the range of $0.9996-1$, and thus the correlation between acquisitions was significant for all the three markers (Figure 4). We conclude that detection of CK18, CA9, and Cadherin 6 is stable and consistent with small variations in between experiments. 


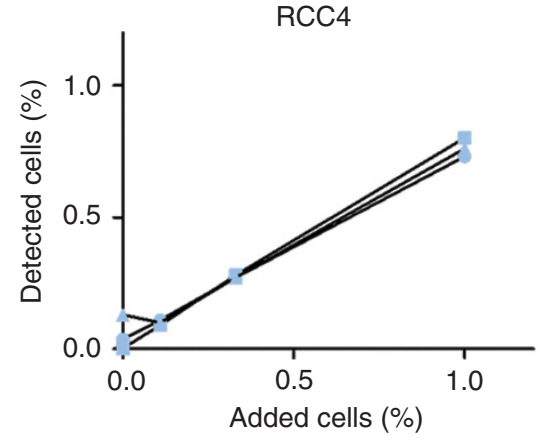

$$
\begin{aligned}
& \text {-CK18; } R^{2}=0.999 \\
& \text {-- CA9; } R^{2}=0.9996 \\
& \text {-- Cad6; } R^{2}=0.9776
\end{aligned}
$$

Figure 3. Correlation between detected and added RCC4 cancer cell line. Samples of PBMCs spiked with renal cancer cell lines RCC4, ACHN3, and CAKI6 (1\%, 0.33\%, and $0.11 \%$ concentrations), with one sample of PBMCs alone. Samples were stained with antibodies against CK18, CA9, and Cadherin 6 and analysed by flow cytometry.

Regression analysis was performed for percentage of positive events of

\begin{tabular}{|c|c|c|c|c|c|c|}
\hline \multirow[b]{2}{*}{ Added cells (\%) } & \multicolumn{3}{|c|}{ Acquisition 1} & \multicolumn{3}{|c|}{ Acquisition 2} \\
\hline & Mean & s.d. & CV (\%) & Mean & s.d. & CV (\%) \\
\hline \multicolumn{7}{|l|}{ CK18 } \\
\hline 1 & 0.729 & 0.048 & 6.58 & 0.720 & 0.026 & 3.61 \\
\hline 0.33 & 0.267 & 0.007 & 2.62 & 0.282 & 0.010 & 3.55 \\
\hline 0.11 & 0.108 & 0.008 & 7.41 & 0.120 & 0.007 & 5.83 \\
\hline 0.037 & 0.069 & 0.005 & 7.25 & 0.083 & 0.006 & 7.23 \\
\hline 0.012 & 0.047 & 0.002 & 4.26 & 0.055 & 0.003 & 5.45 \\
\hline \multicolumn{7}{|l|}{ CA9 } \\
\hline 1 & 0.775 & 0.045 & 5.81 & 0.795 & 0.037 & 4.65 \\
\hline 0.33 & 0.269 & 0.008 & 2.97 & 0.272 & 0.009 & 3.31 \\
\hline 0.11 & 0.087 & 0.007 & 8.05 & 0.090 & 0.006 & 6.67 \\
\hline 0.037 & 0.032 & 0.003 & 9.38 & 0.032 & 0.001 & 3.13 \\
\hline 0.012 & 0.012 & 0.001 & 8.33 & 0.012 & 0.002 & 16.67 \\
\hline \multicolumn{7}{|l|}{ Cadherin 6} \\
\hline 1 & 0.744 & 0.044 & 5.91 & 0.757 & 0.032 & 4.23 \\
\hline 0.33 & 0.267 & 0.008 & 3.00 & 0.269 & 0.009 & 3.35 \\
\hline 0.11 & 0.089 & 0.008 & 8.99 & 0.096 & 0.006 & 6.25 \\
\hline 0.037 & 0.04 & 0.003 & 7.50 & 0.046 & 0.004 & 8.70 \\
\hline 0.012 & 0.017 & 0.002 & 11.76 & 0.022 & 0.002 & 9.09 \\
\hline
\end{tabular}
the three markers in cancer cell line RCC4.

\section{Table 1. Intra-assay variability on RCC4 cell line}

Detection of metastatic cells in sentinel lymph nodes by flow cytometry. To explore a possibility of forthcoming clinical benefit for flow cytometry and CK18, CA9, and Cadherin 6 detection of metastatic renal cell tumours, we investigated freshly retrieved single cells from sentinel lymph nodes from renal tumours patients. Preoperative patient characteristics are listed in Table 2.

In patient 1, three SNs (SN1, 2, and 3) were investigated by flow cytometry analysis. There was presence of Cadherin 6-positive cells in $\mathrm{SN} 1, \mathrm{SN} 2$, and $\mathrm{SN} 3(0.36 \%, 3.4 \%$, and $0.54 \%$, respectively; Figure $5 \mathrm{~A}$ ). This indicates that all the nodes were positive for metastatic cells. However, no expression of CK18 was noted in any of the nodes (Table 3). As all of the investigated sentinel lymph nodes contained metastases, the patient was classified as TNM stage III.

Two non-SNs (nonSN1 and 2) were identified in patient 2. In nonSN1, we could not detect any positive cells for the three markers, indicating that nonSN1 was free from metastasis (Table 3). However, $0.51 \%$ of the cells were positive for CA9 in nonSN2 (Figure 5B) but no positive CK18 and Cadherin 6 cells were detected (Table 3 ). When we stained the isolated tumourinfiltrating lymphocytes (TILs) from the primary tumour, we could
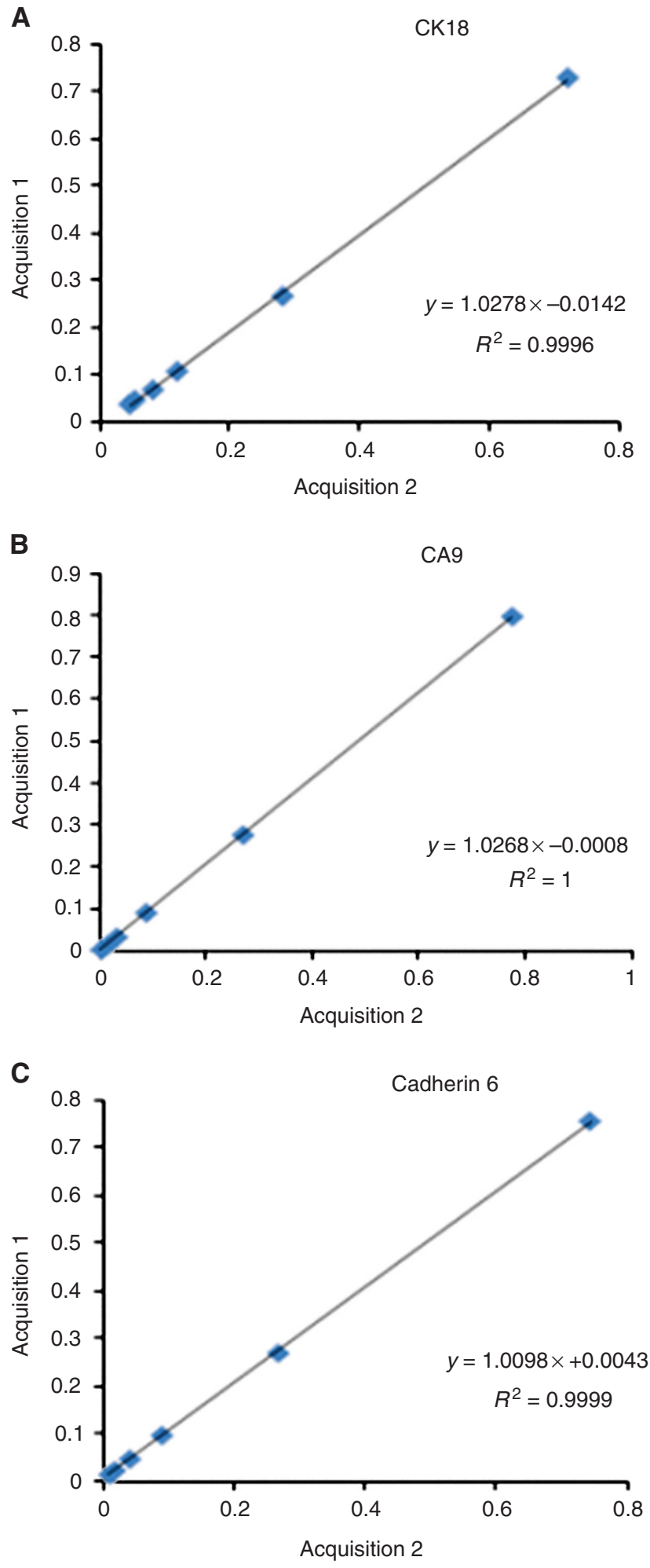

Figure 4. Inter-assay variability evaluation. The RCC4 cancer cells were diluted in PBMCs at concentrations ranging from $1 \%$ to $0.011 \%$. At every concentration, 10 samples were analysed for the presence of tumour cells and mean were calculated. After $8 \mathrm{~h}$, the same samples were reanalysed and inter-assay variability of each marker was assessed using regression analysis. The diagrams show regression analyses of detected amount of Cytokeratin 18 (A), CA9 (B), and Cadherin 6 (C).

detect 24.07\% CK18-positive tumour cells (Figure 5B). The detected cells in TILs were viable tumour cells after enzymatic processing with collagenase and hyaluronidase for TIL isolation. 
Table 2. Patient characteristics

\begin{tabular}{|l|c|c|c|c|c|}
\hline Patients & Gender & $\begin{array}{c}\text { Age } \\
\text { (years) }\end{array}$ & Side & cT stage & cN stage \\
\hline 1 & M & 64 & Left & T2 & N0 \\
\hline 2 & F & 47 & Right & T2 & N0 \\
\hline 3 & F & 69 & Left & T2 & N0 \\
\hline 4 & F & 69 & Left & T2 & NO \\
\hline 5 & M & 54 & Right & T3 & NO \\
\hline \multicolumn{5}{|l}{ Abbreviations: F=female; M=male. }
\end{tabular}

In patient 3 , we analysed four SNs (SN1, SN2, SN3, and SN4) and one non-sentinel node (nonSN1) (Table 3). In SN2 and nonSN1, $3.5 \%$ and $0.47 \%$ CA9-positive cells were detected, respectively, consistent with the presence of $3.44 \%$ Cadherin 6-positive cells in SN2 and 0.26\% Cadherin 6-positive cells in nonSN1. Thus, the presence of metastasis in these nodes was concluded. In SN4, we could also detect $0.05 \%$ CA9-positive cells, indicating the presence of MICs in this node (Table 3 ). Thus, this patient is classified as TNM stage III as well.

Three nodes were extracted from patient 4 and two nodes were analysed (SN2 and nonSN1) (Table 3). In SN2, we could detect $0.26 \%$ Cadherin 6-positive cells and 1.45\% CA9-positive cells, marking the presence of MIC in this node. However, nonSN1 did not show any positive cells for the three tumour cell markers (Table 3).

In patient 5, three nonSNs were identified (nonSN1, nonSN2, and nonSN3). From flow cytometry analysis of the three tumour markers, none of these nodes were shown to have MIC (Table 3 and Figure 5C).

Pathology examination of investigated nodes. Head-to-head comparisons were done per patient between the analysis from flow cytometry and the standard pathology examination. The comparisons between the two methods are listed in Table 4.

The standard anatomical pathology evaluation by H\&E from the renal cancer patient no. 1 showed RCC with clear cell type and nuclear characteristics of Fuhrman grade II. The tumour size was $>7 \mathrm{~cm}$ with no signs of intravascular extension and growth, indicating pT2. All three sentinel lymph nodes identified (SN1, SN2, and SN3) were also analysed by H\&E and they showed no signs of metastasis in the investigated lymph nodes (pN0). Thus, from the pathology report, the TNM staging of RCC in this patient is stage II; contradicting to our flow cytometry detection.

In patient 2, standard pathology examination was carried out after nephrectomy. It revealed the tumour being a renal oncocytoma. The two identified nonSNs (nonSN1 and nonSN2) also underwent analysis and subsequently were non-metastatic by $\mathrm{H} \& \mathrm{E}$.

The results of H\&E examination of patient 3 showed the characteristics of mucinous tubular and spindle cell type of RCC. The tumour size was measured to be $>7 \mathrm{~cm}$ and limited to the kidney (pT2). As this type of RCC has a rare incidence, further IHC examination was carried out that confirmed the diagnosis of mucinous tubular and spindle cell type of RCC. Pathology examination for the identified nodes was also done (SN1, SN2, $\mathrm{SN} 3, \mathrm{SN} 4$, and nonSN1) and showed no signs of metastasis in the investigated nodes. Therefore, based on routine pathology, this patient is in stage II.

The standard pathology examination revealed the tumour size of $>7 \mathrm{~cm}$ and limited to the kidney (pT2) in patient 4 . The tumour was categorised as papillary renal cancer type 1 with some areas of clear cell with nuclear characteristics of Fuhrman grade II. The two nodes extracted (SN2 and nonSN1) were also examined and they showed no positive metastasis ( $\mathrm{pN} 0$ ). This concluded that patient 4 is in stage II.
In patient 5, pathology examination was done and showed that the tumour size was $>7 \mathrm{~cm}$ with breakthrough to the fat capsule without vascular invasion (pT3a). The tumour was characterised as Fuhrman grade II clear cell cancer. The pathology revealed no metastasis from the three investigated nonSNs (nonSN1, nonSN2, and nonSN3) indicating pN0.

\section{DISCUSSION}

In this study we have, for the first time, investigated markers expressed by renal tumour cells by flow cytometry in order to identify ectopic presence of metastatic cells in lymph nodes. We demonstrate that renal cancer cells can be detected at very low cell counts. The detection method is sensitive and reproducible with low intra- and inter-assay variability. Flow cytometry offers several advantages as compared with the gold standard for evaluation of lymph node status in cancer staging. First, flow cytometry is quick and reliable and can be carried out without extensive resources. Moreover, objective analyses of multiple samples can be performed by a technician.

Earlier attempts have been made to describe detection of tumour cells by different kinds of spiking experiments. In this study we carried out spiking experiments using three separate renal cancer cell lines using the same assay. Our results demonstrate that different markers display varying expression (Figure 1). The staining of intracellular cytokeratin demonstrated the most stable expression in the three cell lines, but caused a slightly higher background. However, background staining can potentially be minimised by using additional washes and more optimised staining conditions. Moreover, when samples are compared with isotype control, the unspecific staining is not a problem as it can be deducted. The assay has a very low s.d. for intra-assay variability, in the range of $0.001-0.04 \%$ (Table 1), for expected number of positive cells. Thus, a very small event count above threshold can be considered as indicative for metastasis.

The International Union Against Cancer defines tumour deposits between 0.2 and $2 \mathrm{~mm}$ as MICs and clusters and singlecell infiltrations below this cutoff as isolated tumour cells (ITCs) (Hermanek et al, 1999). Assuming a lymph node is $\sim 10 \times 5 \times 5$ $\mathrm{mm}$ in size, a MIC of $2 \mathrm{~mm}$ equals $\sim 1.6 \%$ of the total number of cells in an average lymph node. Accordingly, a MIC of $0.2 \mathrm{~mm}$ equals $\sim 0.032 \%$ of the total number of cells. From our spiking experiments, we can distinguish a sample that has been spiked with $0.011 \%$ of RCC4 cancer cell lines from a control sample with PBMCs only (Figure 2), indicating that the method is stable and sensitive enough to detect MICs. As demonstrated in our verification experiments with SNs and nonSNs from renal tumour patients, we detected the presence of positive cancer cells in both SNs and nonSNs that range from 0.036 to $3.5 \%$ in eight nodes from all of the five patients. Six of these nodes fulfil the criteria to be MICs with positive cells falling in the range of $0.032-1.6 \%$ (Table 3). However, these results were contradicted with the pathology examination results, as investigation of $\mathrm{H} \& \mathrm{E}$ sections of the lymph nodes were negative. The number of sections investigated was following routine pathology; it is likely that the investigated sections were not representative for the whole lymph node. Thus, the flow cytometry-based investigation demonstrated MICs and changed the TNM staging group from II to III. This might result in a different therapy regiment and prognosis of the patients, in which further clinical evaluations are needed.

In patient 5, we demonstrated the presence of positive cells in the range of $0.004-0.03 \%$ that falls under the criteria of ITCs (Table 3). However, the clinical significance of ITCs is still under debate. It has not clearly been shown whether detection of ITCs in lymph nodes has a clinical impact. In a retrospective study, Joyce 


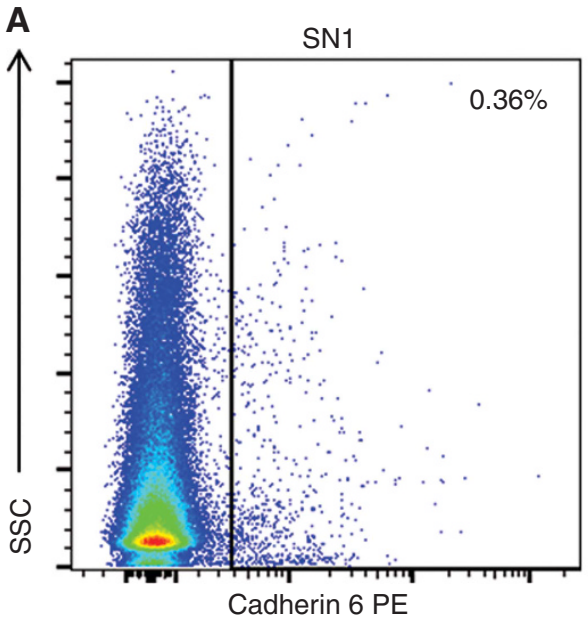

B

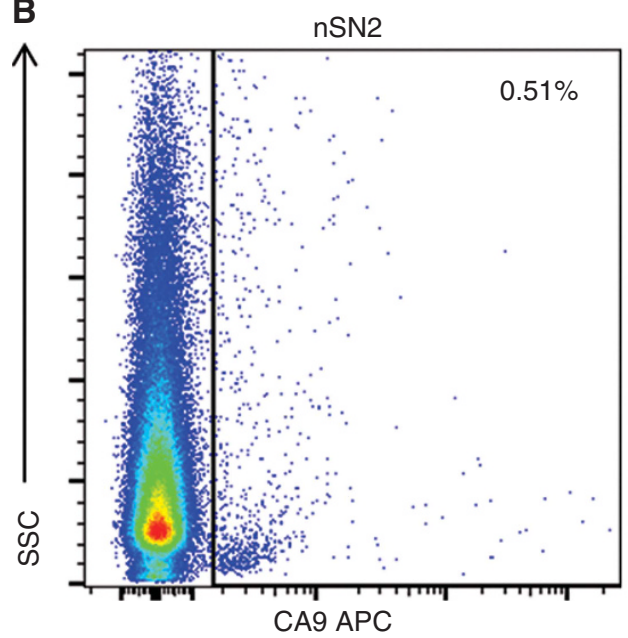

SN2

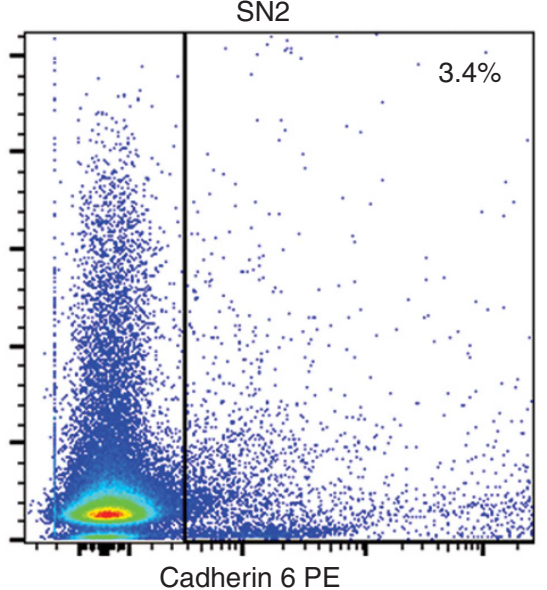

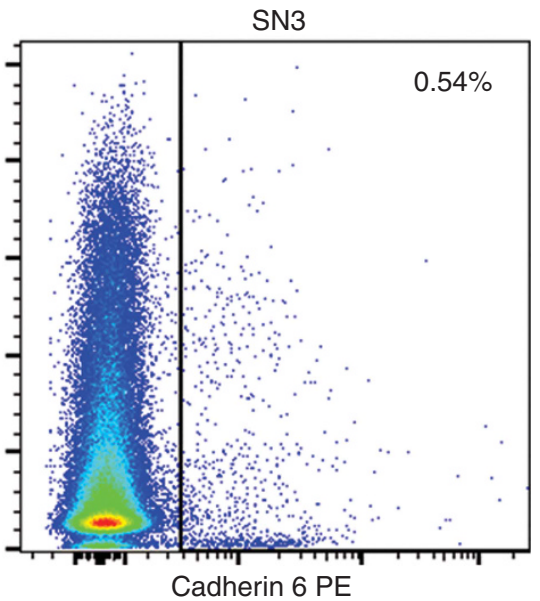

TILS

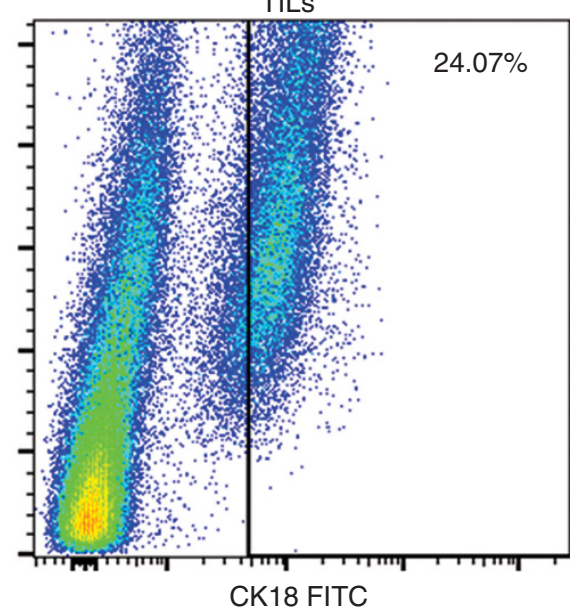

CK18 FITC

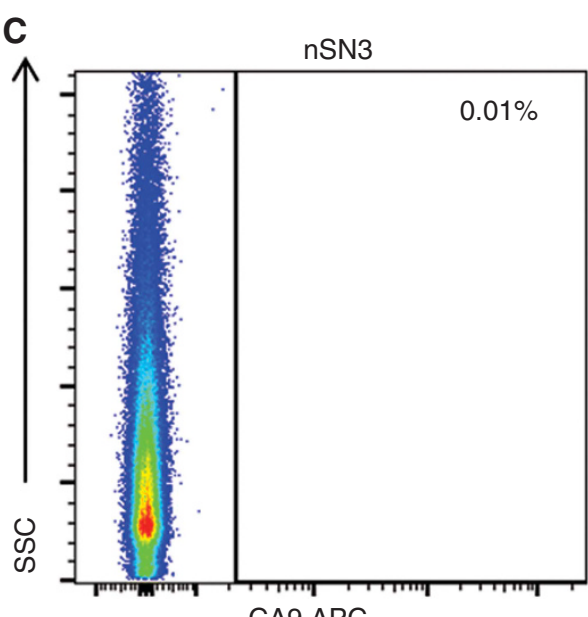

CA9 APC

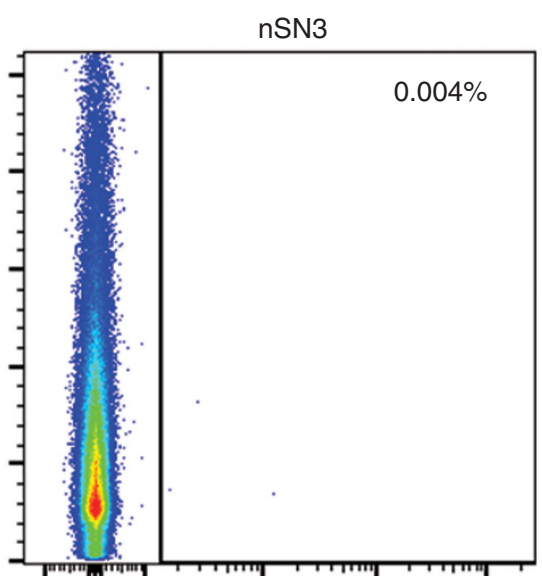

Cadherin 6 PE

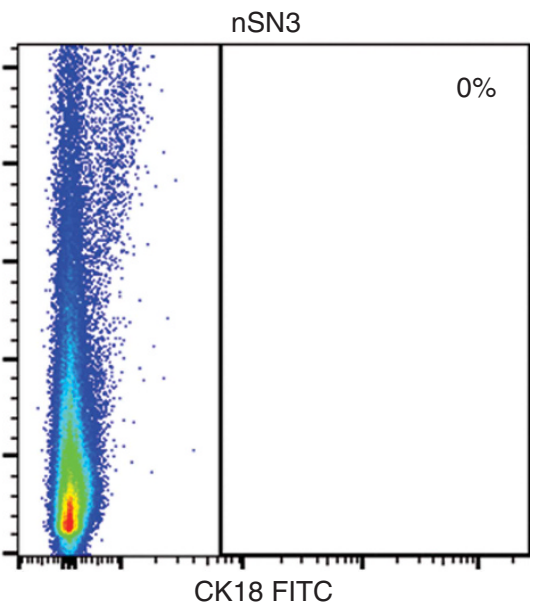

Figure 5. Metastatic cell detection in representative nodes. Single cells from sentinel and non-sentinel nodes from five patients diagnosed with renal tumours were stained intracellularly for CK18 or extracellularly for CA9 and Cadherin 6 before flow cytometry analysis. Positive cells were gated based on isotype control with the definite positive cell percentage shown. (A) Three sentinel nodes were identified in patient 1. Presence of metastasis was detected in all sentinel nodes, marked by the presence of Cadherin 6-positive cells in SN1, SN2, and SN3. (B) In patient 2, two nonsentinel nodes were identified. Metastasis was detected in nonSN2 that was positive for CA9. The CK18-positive population of tumour cells was shown as we stained for TILs in this patient. (C) No micrometastasis was shown in identified three nonSNs from patient 5, with a representative analysis of nonSN3.

et al (2012) showed that the presence of MICs in SNs from patients with breast cancer was associated with axillary disease in $21 \%$ of cases, thus predicting metastatic disease. However, the presence of ITCs in the same cohort did not lead to upstaging (Joyce et al,
2012). Reed et al (2009) made the same conclusion from a prospective cohort and also showed that the presence of MICs, but not ITCs, was a predictor of distant recurrence. As our flow cytometry assay is sensitive enough to detect even ITCs, we 
Table 3. Detection of cancer cells in patient nodes

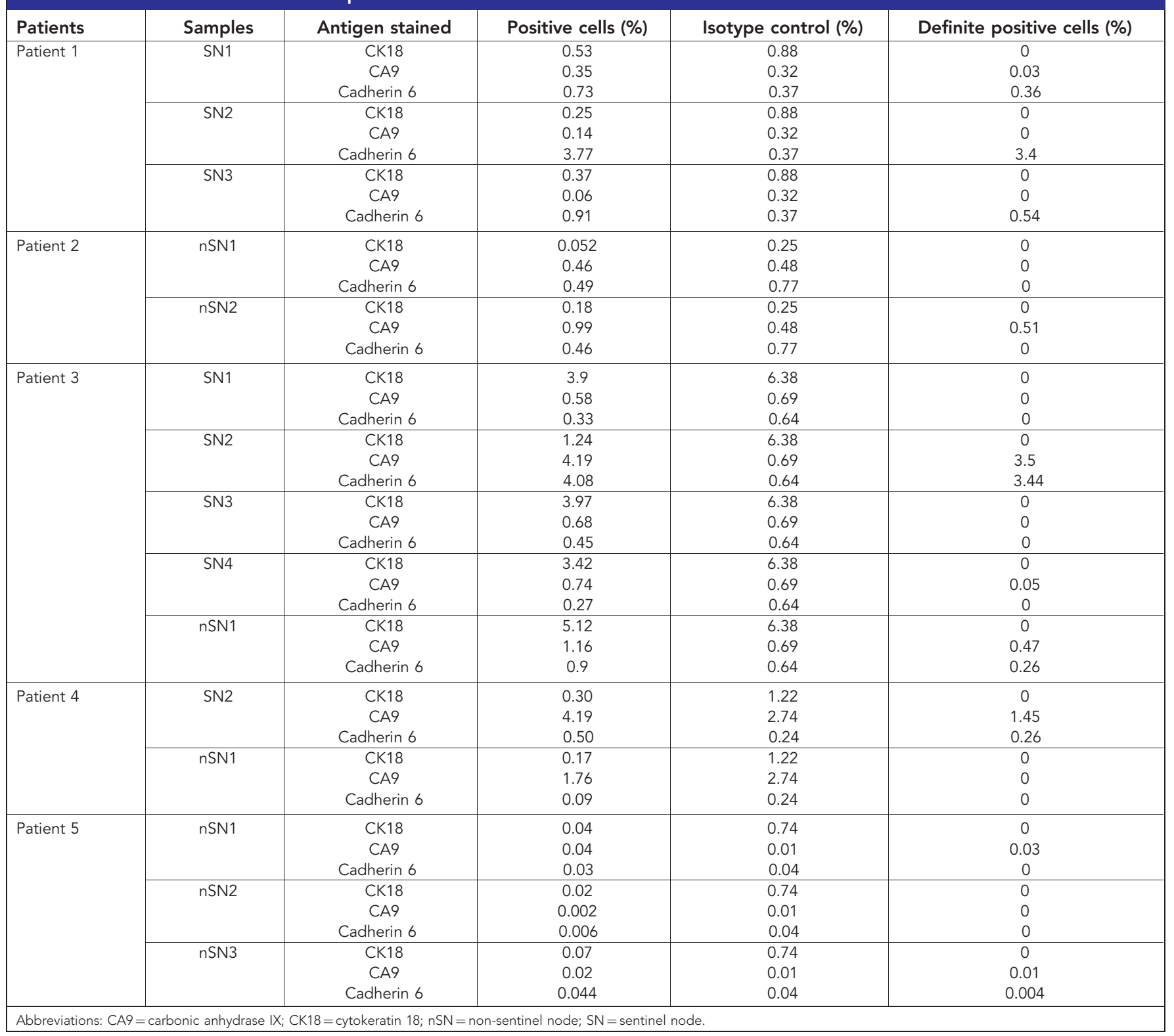

\section{Table 4. Patient outcomes}

\begin{tabular}{|c|c|c|c|c|c|c|c|c|c|}
\hline Patients & $\begin{array}{c}\text { pN stage } \\
\text { (pathology } \\
\text { examination) }\end{array}$ & $\begin{array}{l}\text { pN stage } \\
\text { (flow } \\
\text { cytometry) }\end{array}$ & $\begin{array}{c}\text { Final } \\
\text { histopathology }\end{array}$ & $\begin{array}{c}\text { Total } \\
\text { number of } \\
\text { obtained SNs }\end{array}$ & $\begin{array}{c}\text { Number of } \\
\text { examined } \\
\text { SNs }\end{array}$ & $\begin{array}{c}\text { Number of } \\
\text { metastatic } \\
\text { SNs }\end{array}$ & $\begin{array}{c}\text { Total number } \\
\text { of obtained } \\
\text { nonSNs }\end{array}$ & $\begin{array}{c}\text { Number of } \\
\text { examined } \\
\text { nonSNs }\end{array}$ & $\begin{array}{c}\text { Number of } \\
\text { metastatic } \\
\text { nonSNs }\end{array}$ \\
\hline 1 & $\mathrm{pNO}$ & $\mathrm{pN1}$ & $\mathrm{RCC}$ & 5 & 3 & 3 & 0 & 0 & 0 \\
\hline 2 & $\mathrm{pNO}$ & $\mathrm{pN} 1$ & Oncocytoma & 0 & 0 & 0 & 2 & 2 & 1 \\
\hline 3 & pNO & $\mathrm{pN} 1$ & Muc. spindle & 4 & 4 & 2 & 1 & 1 & 1 \\
\hline 4 & pNO & $\mathrm{pN} 1$ & PRCC & 2 & 1 & 1 & 1 & 1 & 0 \\
\hline 5 & pNO & pNO & $\mathrm{RCC}$ & 0 & 0 & 0 & 3 & 3 & 0 \\
\hline
\end{tabular}

conclude that the method is noninferior to IHC in detecting metastatic disease of clinical importance.

One interesting finding in our experiments is the detection of CA9-positive cells $(0.51 \%)$ in nonSN2 of patient 2 , in which the patient was diagnosed with renal oncocytoma. We have demonstrated that the background staining of CA9 marker was low
$(0.002 \%)$ (Figure $2 \mathrm{~A})$, proving low possibility of false positive. Renal oncocytoma (RO) is a benign epithelial-derived neoplasm in the kidney (Lopez-Beltran et al, 2009). Although benign in nature, there are some reports regarding metastasis of RO (Perez-Ordonez et al, 1997; Oxley et al, 2007), even though it is rare. Other reports also suggest the possible diagnostic uncertainty in differentiating 
RO and chromophobe RCC (chRCC) on H\&E-stained section (Amin et al, 1997; Yusenko, 2010), in which chRCC has malignant feature of metastasis. Moreover, both tumours express similar pattern of CK18 expression ( $\mathrm{Ng}$ et al, 2014), consistent to our flow cytometry result when we stained for TILs in patient 2 (Figure 5B).

In the end, four out of five patients were diagnosed with positive MICs in lymph nodes by flow cytometry, whereas all of them were negative by $\mathrm{H} \& \mathrm{E}$ examination. This gives a promising future of flow cytometry as a diagnostic tool. However, the detected metastatic cells based on our experiment are only detected with one particular marker but not the others. It therefore implies that concomitant staining for the three markers is recommended. Further studies comparing flow cytometry with gold standard IHC in a larger cohort is warranted as it might have therapeutic implications. Moreover, prospective studies to correlate the number of metastatic cells detected in patient's SNs with relapsefree survival (RFS), cause-specific survival (CSS), or overall survival (OS) of the patients are needed.

\section{ACKNOWLEDGEMENTS}

This work was supported by the Swedish cancer society, the Söderberg foundation, the Cancer and Allergy society, the Lundberg foundation, Gustav V foundation, IMTAC and the Marcus and Marianne Wallenberg foundation, Regionala forskningsrådet i Uppsala-Örebroregionen (RFR in UppsalaÖrebro), the Swedish Research Council funding for clinical research in medicine (ALF) in Västerbotten, VLL, Sweden, and the Cancer Research Foundation in Norrland, Sweden. The human renal cancer cell lines RCC4, ACHN-3, and CAKI-6 were kind gifts from Dr P Gutwein.

\section{CONFLICT OF INTEREST}

The authors declare no conflict of interest.

\section{REFERENCES}

Amin MB, Crotty TB, Tickoo SK, Farrow GM (1997) Renal oncocytoma: a reappraisal of morphologic features with clinicopathologic findings in 80 cases. Am J Surg Pathol 21: 1-12.

Benoy IH, Elst H, Van Dam P, Scharpé S, Van Marck E, Vermeulen PB, Dirix LY (2006) Detection of circulating tumour cells in blood by quantitative real-time RT-PCR: effect of pre-analytical time. Clin Chem Lab Med 44: 1082-1087.

Bex A, Vermeeren L, Meinhardt W, Prevoo W, Horenblas S, Valdes Olmos RA (2011) Intraoperative sentinel node identification and sampling in clinically node-negative renal cell carcinoma: initial experience in 20 patients. World J Urol 29: 793-799.

Ferlay J, Shin HR, Bray F, Forman D, Mathers C, Parkin DM (2010) Estimates of worldwide burden of cancer in 2008: GLOBOCAN 2008. Int J Cancer 127: 2893-2917.

Haince JF, Houde M, Beaudry G, L'Espérance S, Garon G, Desaulniers M, Hafer LJ, Heald JI, Lyle S, Grossman SR, Têtu B, Sargent DJ, Fradet Y (2010) Comparison of histopathology and RT-qPCR amplification of guanylyl cyclase $\mathrm{C}$ for detection of colon cancer metastases in lymph nodes. J Clin Pathol 63: 530-537.

Hanahan D, Weinberg RA (2011) Hallmarks of cancer: the next generation. Cell 144: 646-674.

Hermanek P, Hutter RV, Sobin LH, Wittekind C (1999) International Union Against Cancer. Classification of isolated tumor cells and micrometastasis. Cancer 86: 2668-2673.

Joyce DP, Solon JG, Prichard RS, Power C, Hill AD (2012) Is there a requirement for axillary lymph node dissection following identification of micro-metastasis or isolated tumour cells at sentinel node biopsy for breast cancer? Surgeon 10: 326-329.
Karlsson M, Nilsson O, Thörn M, Winqvist O (2008) Detection of metastatic colon cancer cells in sentinel nodes by flow cytometry. J Immunol Methods 334: $122-133$

Langner C, Wegscheider BJ, Ratschek M, Schips L, Zigeuner R (2004) Keratin immunohistochemistry in renal cell carcinoma subtypes and renal oncocytomas: a systematic analysis of 233 tumors. Virchows Arch 444: $127-134$.

Leers MP, Schoffelen RH, Hoop JG, Theunissen PH, Oosterhuis JW, Vd Bijl H, Rahmy A, Tan W, Nap M (2002) Multiparameter flow cytometry as a tool for the detection of micrometastatic tumour cells in the sentinel lymph node procedure of patients with breast cancer. J Clin Pathol 55: 359-366.

Li G, Passebosc-Faure K, Gentil-Perret A, Lambert C, Genin C, Tostain J (2005) Cadherin-6 gene expression in conventional renal cell carcinoma: a useful marker to detect circulating tumor cells. Anticancer Res 25: 377-381.

Li G, Passebosc-Faure K, Lambert C, Gentil-Perret A, Blanc F, Oosterwijk E, Mosnier JF, Genin C, Tostain J (2001) The expression of G250/mn/CA9 antigen by flow cytometry: its possible implication for detection of micrometastatic renal cancer cells. Clin Cancer Res 7: 89-92.

Lim J, Govindarajulu S, Sahu A, Ibrahim N, Magdub S, Cawthorn S (2013) Multiple step-section frozen section sentinel lymph node biopsy-a review of 717 patients. Breast 22: 639-642.

Lopez-Beltran A, Carrasco JC, Cheng L, Scarpelli M, Kirkali Z, Montironi R (2009) 2009 update on the classification of renal epithelial tumors in adults. Int J Urol 16: 432-443.

Marits P, Karlsson M, Dahl K, Larsson P, Wanders A, Thörn M, Winqvist O (2006) Sentinel node lymphocytes: tumour reactive lymphocytes identified intraoperatively for the use in immunotherapy of colon cancer. Br J Cancer 94: $1478-1484$.

Marshall FF (2005) The level of cadherin-6 mRNA in peripheral blood is associated with the site of metastasis and with the subsequent occurrence of metastases in renal cell carcinoma. J Urol 173: 1919.

Messai Y, Noman MZ, Derouiche A, Kourda N, Akalay I, Hasmim M, Stasik I, Ben Jilani S, Chebil M, Caignard A, Azzarone B, Gati A, Ben Ammar Elgaaied A, Chouaib S (2010) Cytokeratin 18 expression pattern correlates with renal cell carcinoma progression: relationship with Snail. Int J Oncol 36: $1145-1154$.

Ng KL, Rajandram R, Morais C, Yap NY, Samaratunga H, Gobe GC, Wood ST (2014) Differentiation of oncocytoma from chromophobe renal cell carcinoma (RCC): can novel molecular biomarkers help solve an old problem? J Clin Pathol 67: 97-104.

Oxley JD, Sullivan J, Mitchelmore A, Gillatt DA (2007) Metastatic renal oncocytoma. J Clin Pathol 60: 720-722.

Pantuck AJ, Zisman A, Dorey F, Chao DH, Han KR, Said J, Gitlitz B, Belldegrun AS, Figlin RA (2003) Renal cell carcinoma with retroperitoneal lymph nodes. Impact on survival and benefits of immunotherapy. Cancer 97: 2995-3002.

Perez-Ordonez B, Hamed G, Campbell S, Erlandson RA, Russo P, Gaudin PB, Reuter VE (1997) Renal oncocytoma: a clinicopathologic study of 70 cases. Am J Surg Pathol 21: 871-883.

Reed J, Rosman M, Verbanac KM, Mannie A, Cheng Z, Tafra L (2009) Prognostic implications of isolated tumor cells and micrometastases in sentinel nodes of patients with invasive breast cancer: 10-year analysis of patients enrolled in the prospective East Carolina University/Anne Arundel Medical Center Sentinel Node Multicenter Study. J Am Coll Surg 208: $333-340$

Sherif AM, Eriksson E, Thorn M, Vasko J, Riklund K, Ohberg L, Ljungberg BJ (2012) Sentinel node detection in renal cell carcinoma. A feasibility study for detection of tumour-draining lymph nodes. BJU Int 109: 1134-1139.

Soyupak B, Erdoğan S, Ergin M, Seydaoğlu G, Kuzgunbay B, Tansuğ Z (2005) CA9 expression as a prognostic factor in renal clear cell carcinoma. Urol Int 74: 68-73.

Tschmelitsch J, Klimstra DS, Cohen AM (2000) Lymph node micrometastases do not predict relapse in stage II colon cancer. Ann Surg Oncol 7: 601-608.

Ulmer AJ, Scholz W, Ernst M, Brandt E, Flad HD (1984) Isolation and subfractionation of human peripheral blood mononuclear cells (PBMC) by density gradient centrifugation on Percoll. Immunobiology 166: 238-250.

Vasselli JR, Yang JC, Linehan WM, White DE, Rosenberg SA, Walther MM (2001) Lack of retroperitoneal lymphadenopathy 
predicts survival of patients with metastatic renal cell carcinoma. J Urol 166: 68-72.

Weaver DL, Krag DN, Manna EA, Ashikaga T, Harlow SP, Bauer KD (2003) Comparison of pathologist-detected and automated computer-assisted image analysis detected sentinel lymph node micrometastases in breast cancer. Mod Pathol 16: 1159-1163.

Weigelt B, Verduijn P, Bosma AJ, Rutgers EJ, Peterse HL, van't Veer LJ (2004) Detection of metastases in sentinel lymph nodes of breast cancer patients by multiple mRNA markers. $\mathrm{Br} J$ Cancer 90: 1531-1537.
Yusenko MV (2010) Molecular pathology of renal oncocytoma: a review. Int J Urol 17: 602-612.

This work is published under the standard license to publish agreement. After 12 months the work will become freely available and the license terms will switch to a Creative Commons AttributionNonCommercial-Share Alike 4.0 Unported License. 